\title{
CFD Analysis on the Effect of Radial Gap on Impeller-Diffuser Flow Interaction as well as on the Flow Characteristics of a Centrifugal Fan
}

\author{
K. Vasudeva Karanth and N. Yagnesh Sharma \\ Department of Mechanical and Manufacturing Engineering, Manipal Institute of Technology, Manipal, Karnataka 576104, India \\ Correspondence should be addressed to K. Vasudeva Karanth, kvkaranth@gmail.com
}

Received 2 December 2008; Accepted 4 February 2009

Recommended by Yasuyuki Yokono

\begin{abstract}
The flow between the impeller exit and the diffuser entry (i.e., in the radial gap is generally considered to be complex). With the development of PIV and CFD tools such as moving mesh techniques, it is now possible to arrive at a prudent solution compatible with the physical nature of flow. In this work, numerical methodology involving moving mesh technique is used in predicting the real flow behavior, as exhibited when a target blade of the impeller is made to move past corresponding vane on the diffuser. Many research works have been undertaken using experimental and numerical methods on the impeller-diffuser interactive phenomenon. It is found from the literature that the effect of radial gap between impeller and diffuser on the interaction and on the performance of the fan has not been the focus of attention. Hence numerical analysis is undertaken in this work to explore and predict the flow behavior due to the radial gap. This has revealed the presence of an optimum radial gap which could provide better design characteristics or lower loss coefficient. It is found that there is a better energy conversion by the impeller and enhanced energy transformation by the diffuser, corresponding to optimum radial gap. The overall efficiency also found to increase for relatively larger gap.
\end{abstract}

Copyright ( $) 2009$ K. V. Karanth and N. Y. Sharma. This is an open access article distributed under the Creative Commons Attribution License, which permits unrestricted use, distribution, and reproduction in any medium, provided the original work is properly cited.

\section{Introduction}

A host of articles [1-16] is available which explicitly explore the impeller diffuser interactive phenomenon by both experimental and numerical methods.

Ubaldi et al. [1] attributed principal cause of the high loss levels observed in the diffuser due to the strong spanwise distortion in swirl angle at inlet, which initiates a strong hub/corner stall. Qin and Tsukamoto [2] has calculated the unsteady flow caused by the interaction between impeller and diffuser vanes in a diffuser pump by using the singularity method.

According to Justen et al. [3], the time-dependent pressure distribution on the diffuser front wall and on the suction and pressure surfaces of the diffuser vanes reveal that the semivaned space mainly the region near the vane suction side is influenced by the unsteady impeller-diffuser interaction and that the pressure fluctuations appear to be distinctly higher than the pressure fluctuations in the vaneless space. Shi and Tsukamoto [4] in their study have shown that the Navier-Stokes code with the $k-\varepsilon$ model is found to be capable of predicting pressure fluctuations in the diffuser.

Sinha et al. $[5,6]$ have carried out quantitative visualization of centrifugal pump with diffuser vanes. The article by Meakhail et al. [7] deals with PIV applied to the study of unsteady impeller-vaneless diffuser interaction in centrifugal fan where measurements were applied to extract the unsteady flow at the exit part of the impeller. In another study by Meakhail et al. [8] an attempt to help understanding the complex unsteady flow associated with the interaction between the impeller and its vaned diffuser has been made. In their two-part paper, Ziegler et al. [9] have presented an experimental investigation of the effect of impeller-diffuser interaction on the unsteady flow and the time-averaged flow field in the interactive region 
of impeller and diffuser. Akinori and Hisasada [10] have investigated the pressure fluctuations in the downstream of the vaned diffuser of a centrifugal pump impeller where they found the potential interaction between the impeller and the diffuser blades more strongly than the impellerwake interaction. Cui [11] has carried out a comparative study of unsteady flow in a transonic centrifugal compressor with vaneless and vaned diffusers. A part of the current work is validated with the results obtained by Meakhail and Park [12], in which they explore the study of impellerdiffuser-volute interaction in a centrifugal fan. These authors report measurement data in the region between the impeller and vaned diffuser and have obtained results of numerical flow simulation of the whole machine. Feng et al. [13] have carried out numerical simulations on impellerdiffuser interactions in radial diffuser pumps to investigate the unsteady flow and pressure fluctuations on the blade and vane surfaces. Different operating points, different blade number configurations, and different radial gaps between the impeller and diffuser have been examined to study their effects on the unsteady flow. They have found that flow rate, blade number configuration, and radial gap influence significantly the pressure fluctuation and associated unsteady effects in the diffuser pumps. Khelladi et al. [14] have carried out the numerical unsteady flow analysis in a vaned centrifugal fan. Majidi [15] has used a CFD code with sliding mesh technique on a centrifugal pump to consider the impeller/volute interaction. The results obtained by him show that the flow in the impeller and volute casing is periodically unsteady and confirm the circumferential distortion of the pressure distribution at the impeller outlet and in the volute casing. Ibaraki et al. [16] in their work have found that a complex three-dimensional flow with distortion between the shroud and the hub is observed.

It is clear from the above literature survey that the effect of radial gap on the system performance as well as on the impeller-diffuser interaction in a centrifugal fan has not been explored well so far. Hence a numerical modeling of the flow domain which includes a portion of the inlet to the impeller as well as the diffuser with volute casing has been carried out, and moving mesh technique has been adopted for unsteady flow simulation of the centrifugal fan in this analysis.

\section{Numerical Modeling}

2.1. Geometry and Grid Generation. The centrifugal fan stage consists of an inlet region, an impeller, a vaned diffuser, and a volute casing (Figure 1). The impeller consists of thirteen 2$\mathrm{D}$ backward swept blades with an exit angle of $76^{\circ}$ relative to the tangential direction. The radial gap between the impeller outlet and the diffuser inlet is $15 \%$ of the impeller outlet radius. The diffuser ring has also the same number of vanes as that of the impeller. All the blades are of $5 \mathrm{~mm}$ thickness. The specifications of the fan stage are illustrated in Table 1.

The technical paper by Meakhail and Park [12] forms the basis for geometric modeling in the present work. The model of the fan consists of four parts: the inlet, the impeller, the diffuser, and the volute region. Unstructured

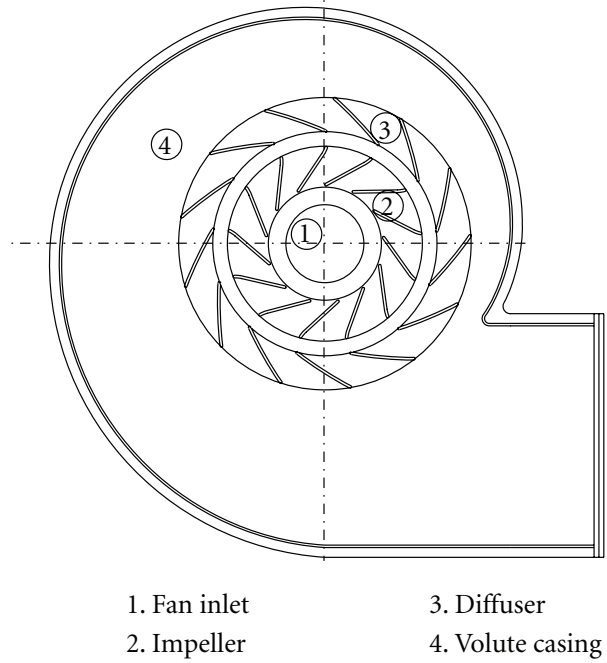

FIgURE 1: Model of the centrifugal fan used in the analysis.

TABLE 1: Specifications of the centrifugal fan.

\begin{tabular}{lc}
\hline \multicolumn{2}{c}{ Centrifugal fan specifications } \\
\hline Impeller inlet radius, $r_{1}$ & $120 \mathrm{~mm}$ \\
Impeller outlet radius, $r_{2}$ & $200 \mathrm{~mm}$ \\
Diffuser inlet radius, $r_{3}$ & $230 \mathrm{~mm}$ \\
Diffuser outlet radius, $r_{4}$ & $300 \mathrm{~mm}$ \\
Volute exit flange width & $450 \mathrm{~mm}$ \\
Width of diffuser blade & $35 \mathrm{~mm}$ \\
Width of volute casing & $90 \mathrm{~mm}$ \\
Impeller inlet vane angle & $30^{\circ}$ \\
Impeller outlet vane angle & $76^{\circ}$ \\
Diffuser inlet vane angle & $23^{\circ}$ \\
Diffuser outlet vane angle & $38^{\circ}$ \\
Number of impeller vanes & 13 \\
Number diffuser vanes & 13 \\
Speed of the fan (RPM) & $1000 \mathrm{rrpm}$ \\
\hline
\end{tabular}

meshing technique is adopted for establishing sliding mesh configuration as the analysis is unsteady as per CFD code [17].

The grid for the volute part of the domain has 163590 nodes and 162113 elements. The diffuser has 163213 nodes and 155106 elements. The impeller has 80971 nodes and 74143 elements. The inlet part of the domain has 5536 and 5190 nodes and elements, respectively. The maximum size of the element is limited to elements having an edge length of $2 \mathrm{~mm}$. However, to establish grid independency a finer model having an element edge length of maximum of $1 \mathrm{~mm}$ is carried out and the variation in the results was found to be less than $2.5 \%$ and hence to save the computational time, elements edge length of maximum $2 \mathrm{~mm}$ size is adopted. Figure 2 shows the meshed domain and it can be observed that a finer mesh is adopted near the surface of the impeller and diffuser vanes to capture the boundary layer effects using a suitable sizing algorithm as in CFD code [17]. 


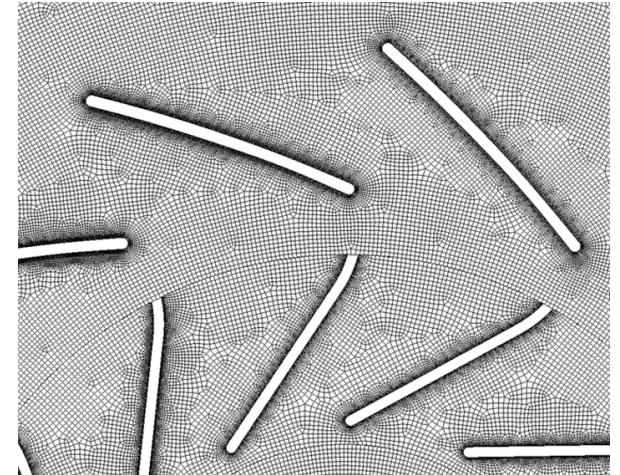

Figure 2: A view of the meshed portion between the impeller and diffuser of the centrifugal fan.

2.2. Unsteady Calculations Setup. Two-dimensional, unsteady Reynolds-averaged Navier-Stokes equations set to polar coordinate system are solved by the CFD code [17]. To obtain the flow characteristic and efficiency curves of the fan, total pressure (gage) is applied at the inlet, and static pressure (gage) is applied at the flange exit as the boundary condition. However, for comparing the configurations with different radial gap, an absolute velocity of $5 \mathrm{~m} / \mathrm{s}$ which corresponds to the design point mass flow rate of the optimal configuration is imposed at the inlet and a zero-gradient outflow condition of all flow properties is applied at the flange exit of the fan, assuming fully developed flow conditions.

A no-slip wall condition is specified for the flow at the wall boundaries of the blades, the vanes, and also the volute casing. The turbulence is simulated using a standard $k-\varepsilon$ model [17]. Turbulence intensity of $5 \%$ and a turbulent length scale of $0.5 \mathrm{~m}$ which is the cube root of the domain volume are adopted in the study. The unsteady formulation used is a second-order implicit velocity formulation, and the solver is pressure based [17]. The pressure-velocity coupling is done using SIMPLE algorithm, and discretization is carried out using the power law scheme. The interface between the impeller and the diffuser is set to sliding mesh in which the relative position between the rotor and the stator is updated with each time step. The time step $\Delta t$ is set to 0.0001 second, corresponding to the advance of the impeller by $\Delta y=0.61^{\circ}$ per time step for a rated speed of $1000 \mathrm{RPM}$ to establish stability criterion. The maximum number of iterations for each time step is set to 30 in order to reduce all maximum residuals to a value below $10^{-5}$. Since the nature of flow is unsteady, it is required to carry out the numerical analysis until the transient fluctuations of the flow field become time periodic as judged by the pressure fluctuations at salient locations in the domain of the flow. In the present analysis this has been achieved after two complete rotations of the impeller. The salient locations chosen are the surfaces corresponding to inlet to the impeller, impeller exit, diffuser exit, impeller vanes, diffuser vanes, and the exit flange of the volute casing. The time- and area-weighted averages for the pressure and velocity fluctuations at each salient location in the computational domain are recorded corresponding to each rotation of the impeller by time step advancement. The

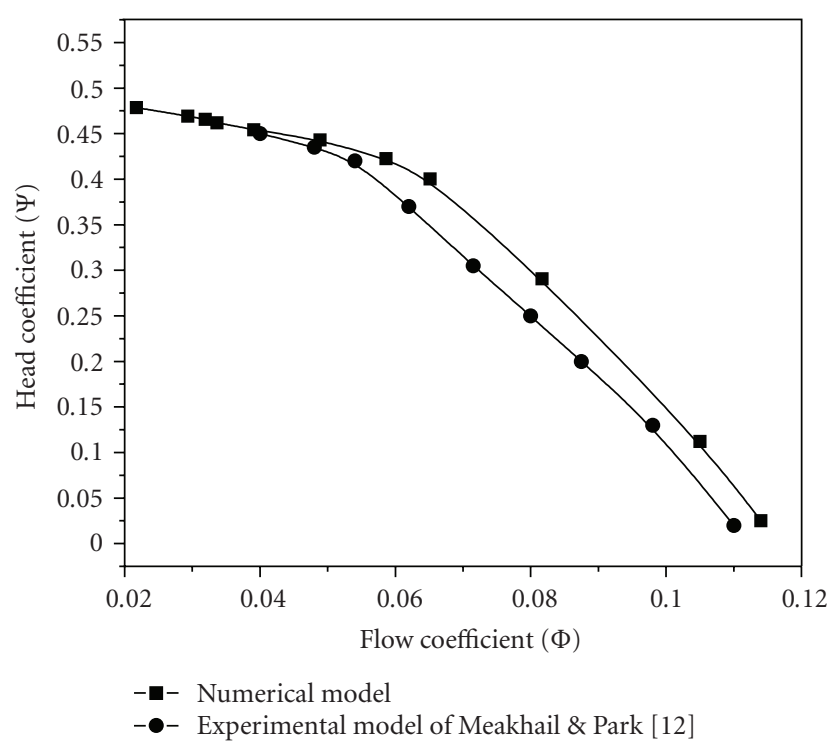

Figure 3: Validation characteristics curve of head coefficient with flow coefficient.

static pressure recovery coefficient and the total pressure loss coefficient for the diffusing domains of the fan are calculated based on the weighted averages [17] and are plotted with respect to time steps.

2.3. Validation of the Model. The numerical model for the whole field flow calculations is validated by calibrating the results of the current numerical work with the experimental work carried out by Meakhail and Park [12].

The graph shown in Figure 3 captures the validation results for the current work with the work cited above.

The validation curve is a head coefficient versus flow coefficient curve which shows a decrease in the head coefficient as the flow coefficient increases as is required for a backward swept impeller blade. The validation shows a close agreement between the present numerical model and the experimental model of Meakhail and Park [12].

\subsection{Geometric Configurations for Impeller-Diffuser Radial} Gap. A total of six different configurations are generated by varying the radial gap between the impeller and the diffuser. The outer radii of the impeller and the diffuser are kept constant at $200 \mathrm{~mm}$ and $300 \mathrm{~mm}$, respectively. However, the inlet radius of the diffuser is changed to achieve the radial gap variation.Configurations $\mathrm{A}, \mathrm{B}, \mathrm{C}, \mathrm{D}, \mathrm{E}$, and $\mathrm{F}$ are having a radial gap ratio " $R_{\mathrm{gr}}$ " of $0.05,0.1,0.15,0.2,0.25$, and 0.30 , respectively.

\section{Results and Discussion}

The head coefficient versus flow coefficient characteristic curves for all the six configurations is plotted after capturing the area weighted average values of the pressure coefficients and mass averaged flow rates. It is seen from Figures 3 and 4 


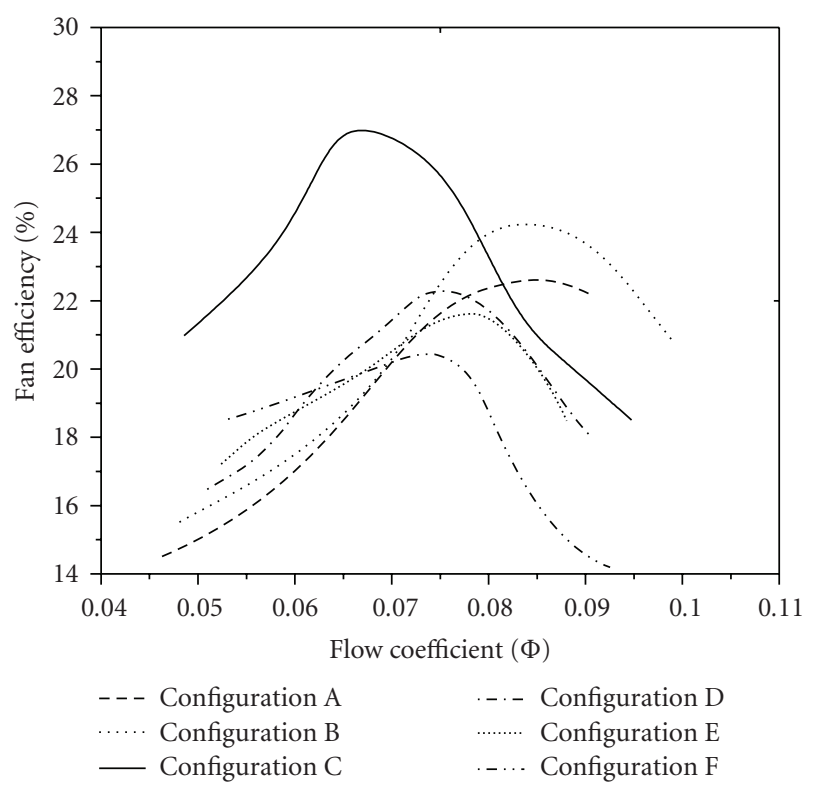

Figure 4: Performance of centrifugal fan (efficiency versus flow coefficient).

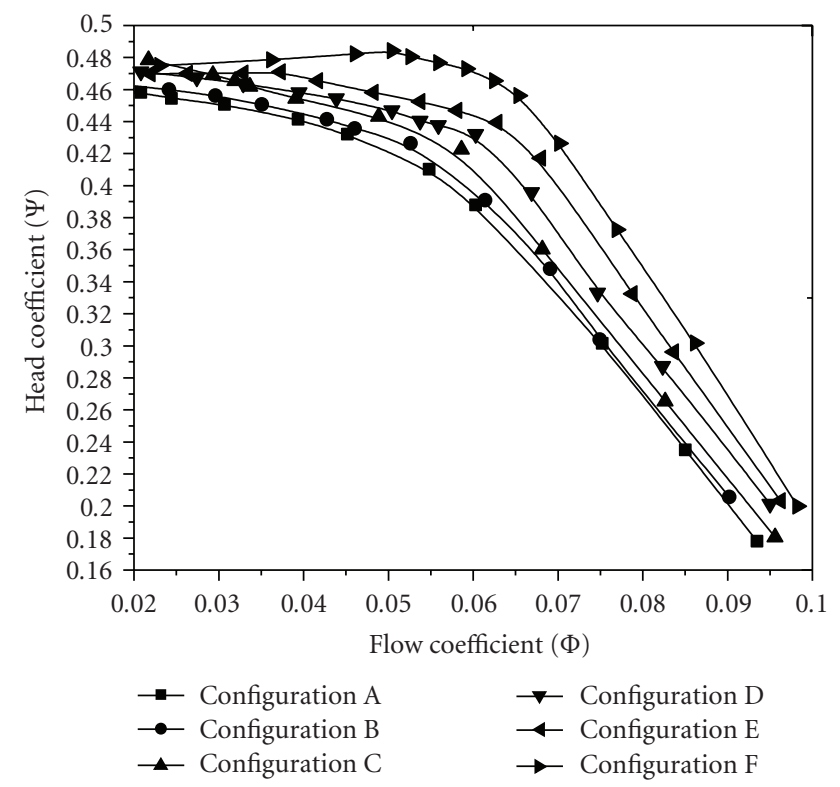

FIGURE 5: Performance characteristics curves for all configurations.

that the design point operation as well as efficiency seems to change with change in radial gap.

From Table 2 and Figure 4 it is observed that the smaller radial gap ratio of 0.05 (configuration $\mathrm{A}$ ) and for the larger radial gap ratio of 0.3 (configuration $\mathrm{F}$ ), the design point mass flow rate is relatively higher than that of configuration $\mathrm{C}$ which has a radial gap ratio of 0.15 . More importantly, the efficiency corresponding to design point operation is found to be higher for configuration C.

Radial gap is required to avoid steep velocity gradients at the diffuser entry region according to Yahya [18]. This allows

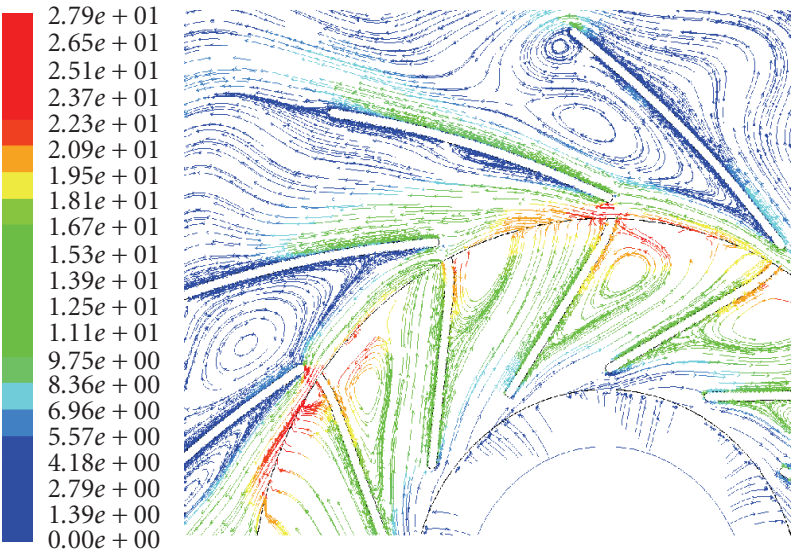

FIGURE 6: Relative velocity plot for configuration A (radial gap ratio $=0.05)$.

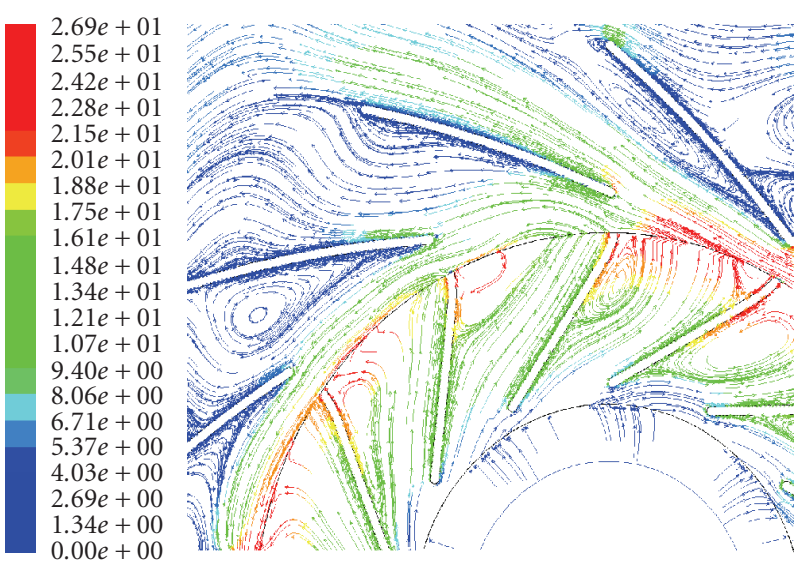

FIGURE 7: Relative velocity plot for configuration B (radial gap ratio $=0.1$ ).

nonuniform flow to mix out and enter the diffuser with lower velocities. Also the flow emanating from the impeller has jets and wakes as clearly seen in the relative velocity vector plots shown in Figures 6, 7, 8, 9, and 10. When such a flow enters diffusing flow passages, the quality of flow differs widely and some of the blades of the diffuser may experience flow separation leading to rotating stall and poor performance.

At smaller radial gap, the flow enters the stationary diffuser almost at the same velocity profile as it leaves the impeller and jets and wakes related to the impeller exit flow do not have a chance to even out. This causes lower diffusion leading to lower diffuser static pressure recovery coefficient and lower overall static pressure recovery coefficient across the fan as shown in Figure 11 as well as lower fan efficiency as shown in Figure 4.

The shifting of the design point operation at lower radial gap ratio of 0.05 may be attributed to the fact that the energetic fluid jetting from the impeller enters the diffuser and decelerates over the diffuser. As a result a large recirculation zone is formed in many of the diffuser blade passages as seen in Figure 6. This will block the flow and hence for peak point operation a higher mass flow rate is 
TABLE 2: Computed flow parameters at design point operation of the fan.

\begin{tabular}{lcccc}
\hline Configuration type & Radial gap ratio $R_{\mathrm{gr}}$ & Flow coefficient $(\Phi)$ & Max. efficiency $\eta(\%)$ & Head coefficient $(\Psi)$ \\
\hline A & 0.05 & 0.085 & 22.84 & 0.235 \\
B & 0.10 & 0.073 & 24.59 & 0.304 \\
C & 0.15 & 0.066 & 27.37 & 0.360 \\
D & 0.20 & 0.074 & 22.63 & 0.333 \\
E & 0.25 & 0.078 & 22.02 & 0.3324 \\
F & 0.30 & 0.076 & 20.99 & 0.372 \\
\hline
\end{tabular}

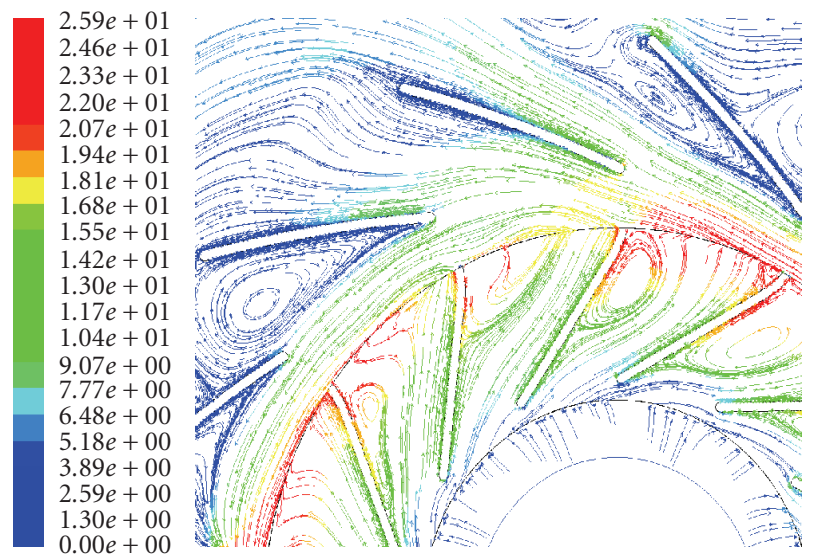

FIGURE 8: Relative velocity plot for configuration C (radial gap ratio $=0.15)$.

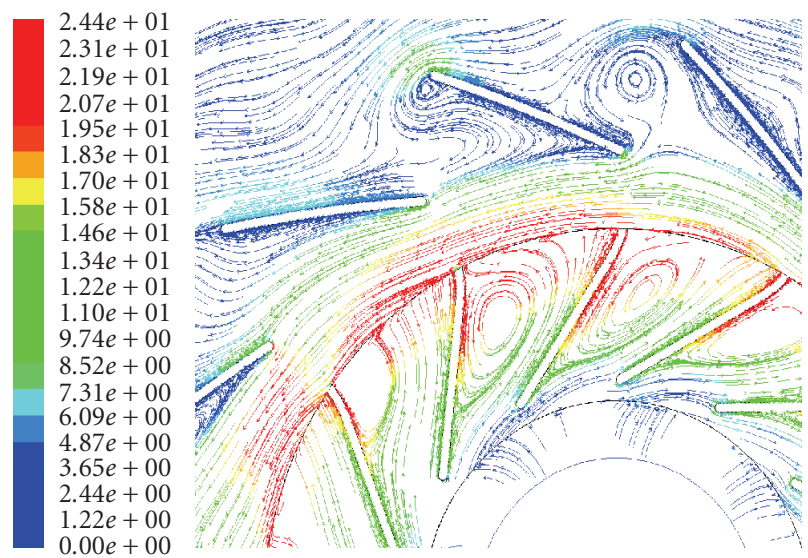

FIGURE 9: Relative velocity plot for configuration D (radial gap ratio $=0.20$ ).

required. Hence there is a perceptible shift in the design point operation for radial gap ratio of 0.05 .

However, when the radial gap is relatively larger, even though the jets and wakes related to the exit flow from the impeller gets evened out, the flow tends to stall in some of the vanes of the diffuser due to change in angle of incidence, as can be seen in Figure 10. This will have detrimental effect on the static pressure rise across the fan leading to poorer efficiency.

It is seen in a contrasting manner that there is a higher mass flow rate corresponding to the design point operation

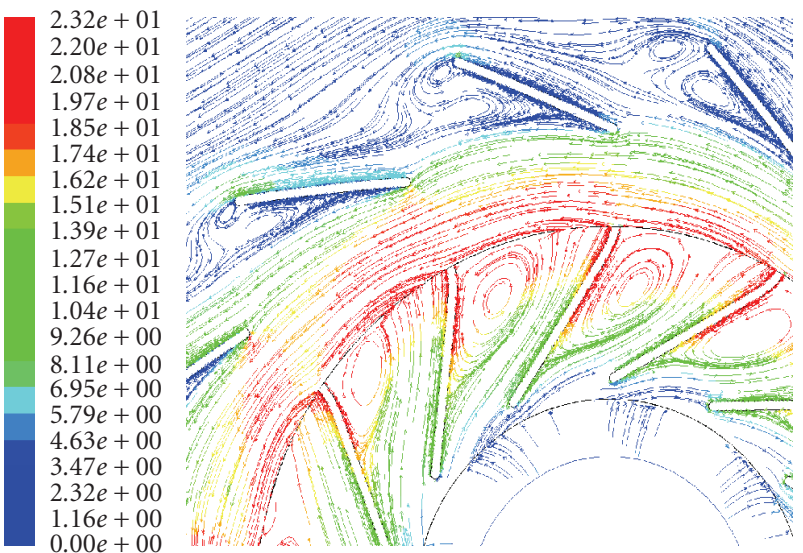

FIGURE 10: Relative velocity plot for configuration E (radial gap ratio $=0.25)$.

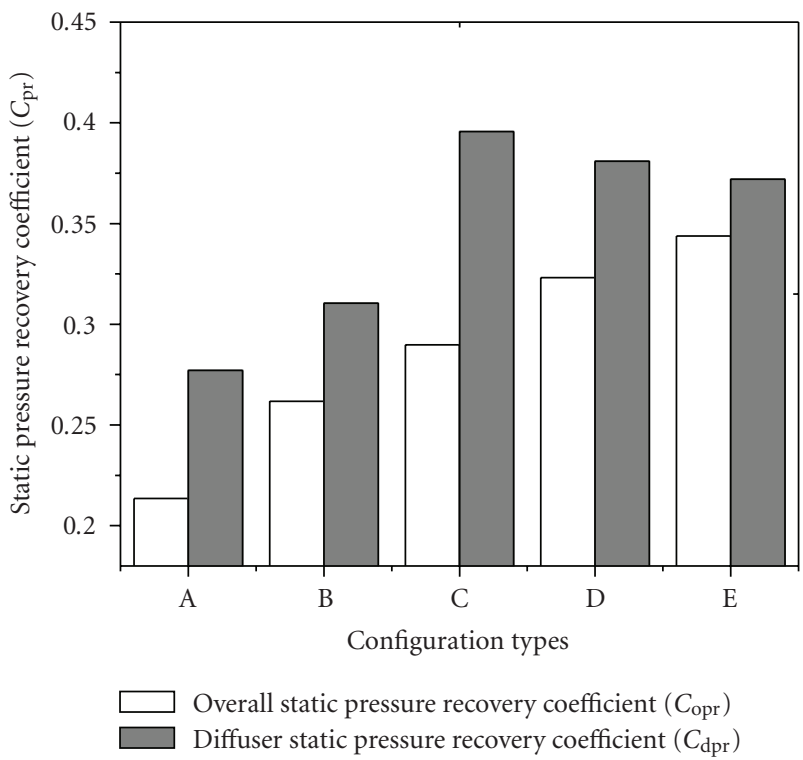

FIGURE 11: Static pressure recovery coefficient.

for the case of larger radial gap ratio of 0.25 from Figure 4 . This can be attributed to stalling process occurring over some of the diffuser vanes due to relatively larger radial gap (Figure 10) which requires a higher mass flow rate to achieve peak point operation. 
The static pressure recovery coefficients and total pressure loss coefficients for various configurations are presented in the form of bar charts in Figures 11 and 12, respectively.

It is seen from Figure 12 that total pressure loss coefficient is higher for the smaller radial gap but for larger radial gap it tends to decrease. This is because of the fact that at larger radial gap, the diffusion passage gets reduced and hence friction losses are lower compared to lower radial gap configuration. Also it is clear from Figure 12 that for configuration $\mathrm{C}$ the total pressure loss coefficient is least compared to configurations $\mathrm{D}$ and $\mathrm{E}$. This is due to the fact that at relatively larger radial gap, the fluid guidance is decreased and hence there is a marginal rise in total pressure loss coefficient.

Hence it can be stated that there must be an optimum radial gap which could provide relatively higher efficiency and also lower mass flow rates to achieve the higher static pressure rise.

It can be seen from Figure 11 that the overall static pressure recovery coefficient increases with the increase in radial gap while the diffuser static pressure recovery coefficient increases up to radial gap ratio of 0.15 (configuration C) and then it decreases. This is also reflected in Figure 12 in which the total pressure loss coefficient for the configuration $\mathrm{C}$ is the lowest. The reason why there is an increase in overall static pressure recovery for larger radial gap corresponding to configurations $\mathrm{E}$ and $\mathrm{F}$ is due to the fact that the slope of the characteristic for these configurations becomes slightly positive for lower mass flow rate as seen in Figure 5. Hence there is an increase in head coefficient, resulting in increase in overall static pressure recovery coefficient. But this can lead to the possibility of unstable surge condition. So a larger radial gap ratio above $R_{\mathrm{gr}}=0.15$ is not preferable. Figure 13 shows the dynamic head coefficient at the design point mass flow rate for various configurations. It is clear from Figure 13 that corresponding to $R_{\mathrm{gr}}=0.15$, the dynamic head is found to be the maximum. This shows that it is possible to have better energy transfer corresponding to this radial gap ratio of $R_{\mathrm{gr}}=0.15$.

Figure 14 shows the impeller static pressure coefficient for different configurations. It is seen from the figure that the configuration $\mathrm{C}$ experiences the maximum static pressure rise. This also can be verified from Figure 8 which shows a marginal reduction in the wake regions in the impeller blade passages. The wake in the impellers for configurations $D$ and $\mathrm{E}$ is seen to increase indicating that a larger radial gap will tend to increase the wake. Hence it becomes quite obvious from the stated facts in the last two paragraphs that there is an optimum radial gap corresponding to $R_{\mathrm{gr}}=0.15$ which provides highest total energy transfer for the impeller blade.

Figure 15 shows the diffuser exit static pressure coefficient for the various configurations. It is seen that for optimum radial gap ratio of 0.15 there is a better static pressure conversion which tallies with the physical explanations earlier given. Figure 16 depicts the amplitude of pressure fluctuations captured at different time steps, at the exit flange of the fan. The fluctuations die down with the increase in radial gap as the fluid particles jetting out at the impeller exit tend to get evened out before the flow enters the

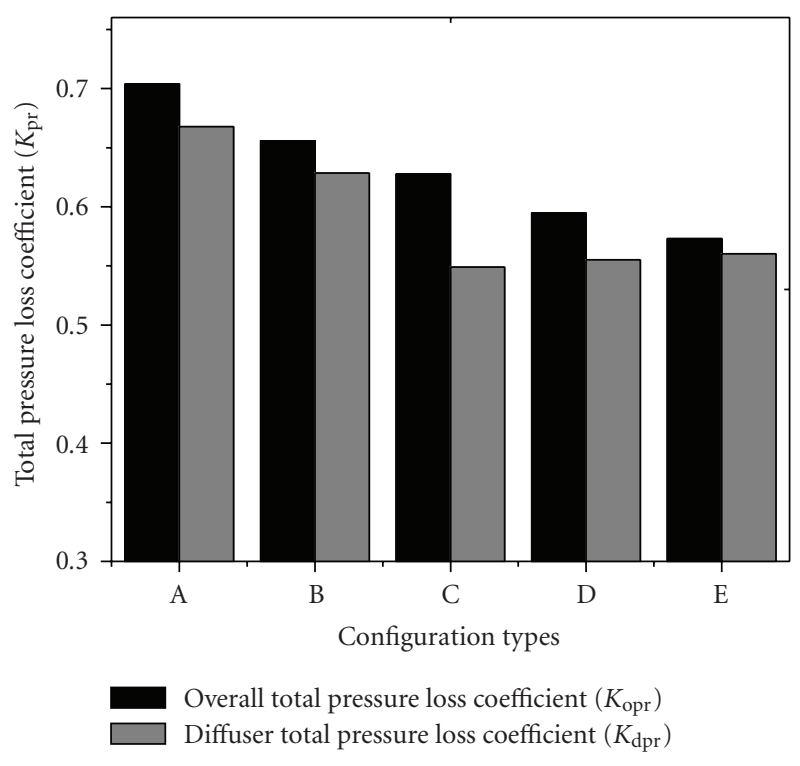

FIGURE 12: Total pressure loss coefficient.

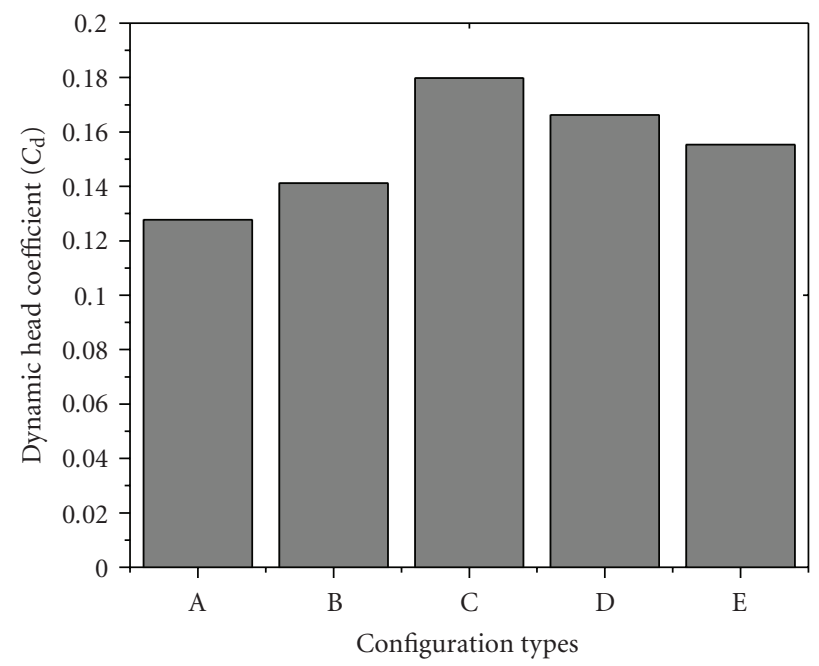

FIGURE 13: Dynamic head coefficient at the design point mass flow rate of configuration $\mathrm{C}$ (inlet velocity of $5 \mathrm{~m} / \mathrm{s}$ ).

vaned diffusers and this agrees with the result obtained by Feng et al. [13]. It can, therefore, be conclusively stated that there is an optimum radial gap which could help providing maximum energy transfer by the impeller blades as well as maximum energy conversion by diffuser vanes.

\section{Conclusion}

The following conclusions can be drawn from the above study.

(1) As a major inference from the above analysis, it is found that there is an optimum radial gap at which better dynamic and static heads are developed by the impeller blades as well as better energy conversion by diffuser vanes. 


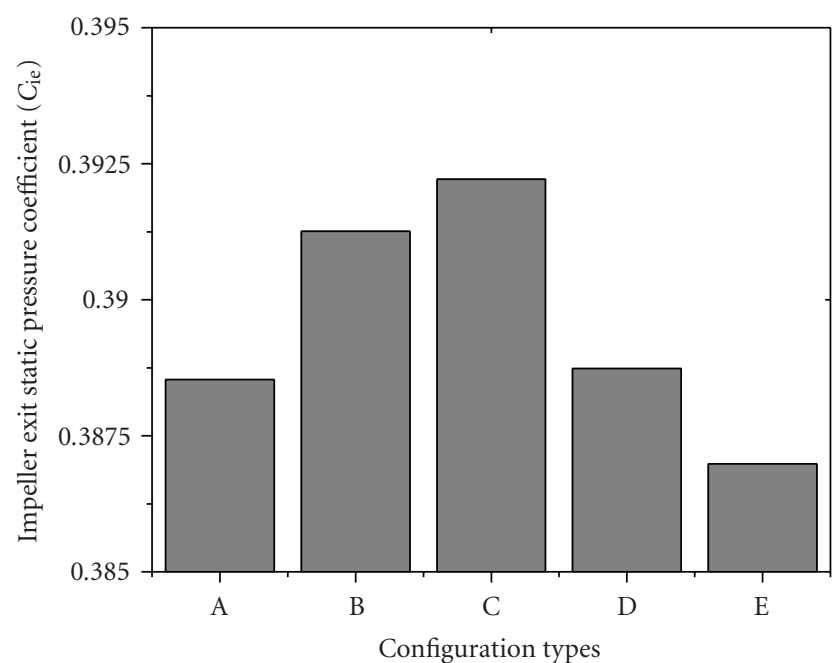

Figure 14: Impeller exit static pressure coefficient for the various configurations.

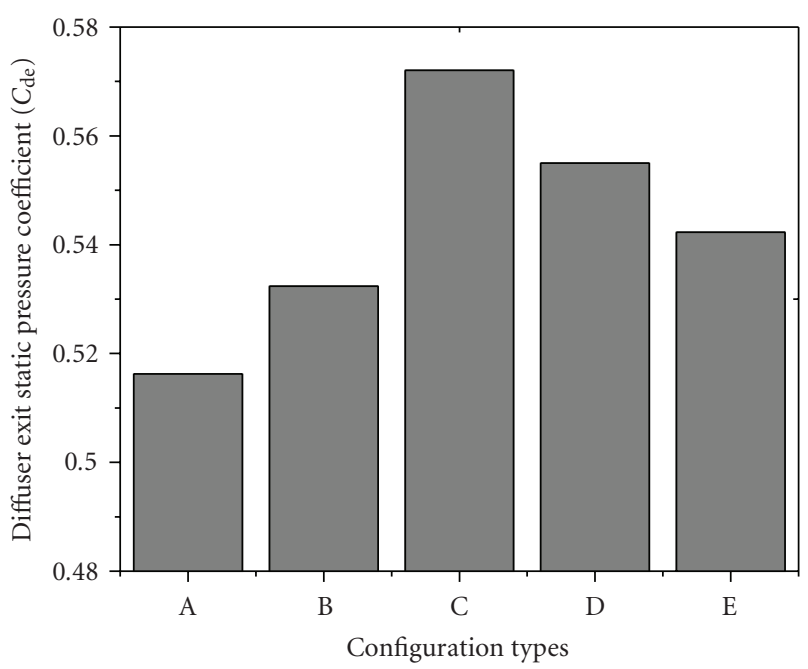

FIGURE 15: Diffuser exit static pressure coefficient for the various configurations.

(2) The above-mentioned facts lead to maximum efficiency of the centrifugal fan as observed in the study.

(3) There appears to be greater degree of stalling of the flow above or below the optimum radial gap.

(4) The static pressure recovery and total pressure loss for the diffusing components of the fan change with the radial gap.

(5) The larger is the radial gap, the smaller are the pressure fluctuations at the exit flange of the fan.

(6) The jet and wake phenomena as seen in all the impeller passages are influenced by the radial gap between impeller and diffuser.

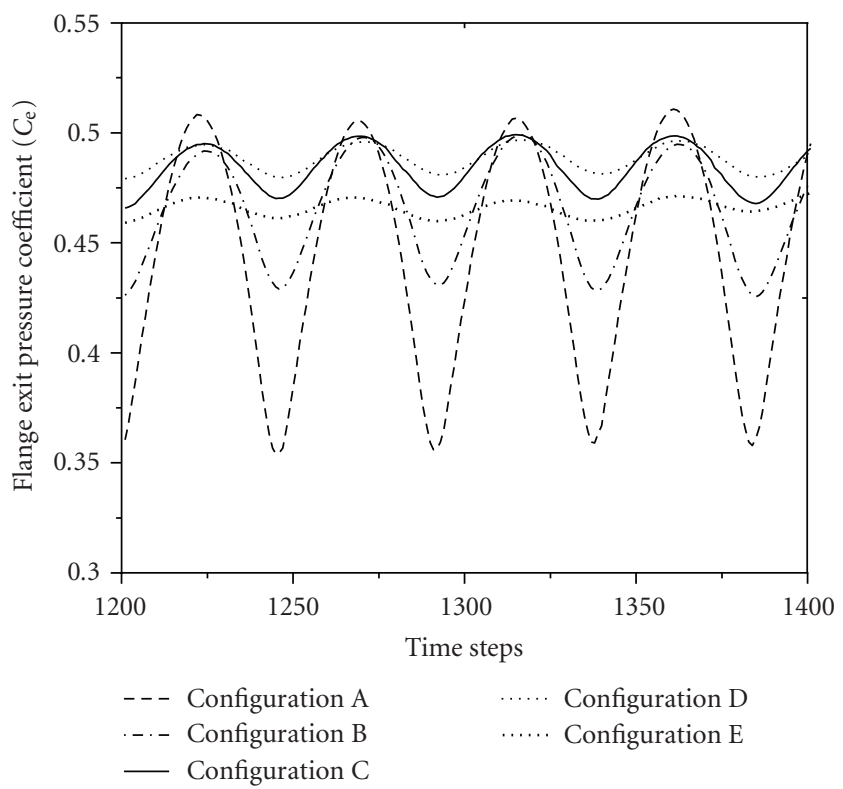

FIgURE 16: Static pressure coefficient at the exit flange of the fan versus time steps.

\section{Nomenclature}

$p_{1}: \quad$ Static pressure at impeller inlet $(\mathrm{Pa})$

$p_{2}: \quad$ Static pressure at impeller exit $(\mathrm{Pa})$

$p_{3}: \quad$ Static pressure at diffuser exit $(\mathrm{Pa})$

$p_{4}: \quad$ Static pressure at flange exit $(\mathrm{Pa})$

$p_{\mathrm{t} 2}:$ Total pressure at impeller exit $(\mathrm{Pa})$

$p_{\mathrm{t} 3}$ : Total pressure at diffuser exit $(\mathrm{Pa})$

$p_{\mathrm{t} 4}$ : Total pressure at flange exit $(\mathrm{Pa})$

$U_{2}$ : Tangential velocity at impeller exit $(\mathrm{m} / \mathrm{s})$

$C_{2 \mathrm{u}}$ : Absolute tangential velocity at impeller exit $(\mathrm{m} / \mathrm{s})$

$\rho: \quad$ Air density $\left(\mathrm{kg} / \mathrm{m}^{3}\right)$

Q: $\quad$ Volume flow rate $\left(\mathrm{m}^{3} / \mathrm{s}\right)$

$\Phi: \quad$ Flow coefficient $=\left(Q / \pi r_{2}^{2} U_{2}\right)$

$\Psi: \quad$ Head coefficient $=\left(\left(p_{4}-p_{1}\right) / \rho U_{2}^{2}\right)$

$\gamma: \quad$ The angle of advance of a given impeller blade to its next adjacent blade position

$\eta: \quad$ Fan efficiency $=\left(\left(P_{\mathrm{t} 2}-P_{\mathrm{t} 4}\right) / \rho C_{2 \mathrm{u}} U_{2}\right) \times 100$

$C_{\text {opr }}$ : Overall static pressure recovery coefficient $=\left(p_{4}-p_{2}\right) /\left(p_{\mathrm{t} 2}-p_{2}\right)$

$K_{\text {opr }}$ : Overall total pressure loss coefficient $=\left(p_{\mathrm{t} 2}-p_{\mathrm{t} 4}\right) /\left(p_{\mathrm{t} 2}-p_{2}\right)$

$C_{\mathrm{dpr}}$ : Diffuser static pressure recovery coefficient $=\left(p_{3}-p_{2}\right) /\left(p_{\mathrm{t} 2}-p_{2}\right)$

$K_{\mathrm{dpr}}$ : Diffuser total pressure loss coefficient $=\left(p_{\mathrm{t} 2}-p_{\mathrm{t} 3}\right) /\left(p_{\mathrm{t} 2}-p_{2}\right)$

$C_{\mathrm{ie}}: \quad$ Impeller exit static pressure coefficient $=p_{2} / \rho U_{2}^{2}$

$C_{\mathrm{de}}:$ Diffuser exit static pressure coefficient $=p_{3} / \rho U_{2}^{2}$

$C_{\mathrm{e}}$ : Flange exit static pressure rise coefficient $=\left(p_{4}-p_{1}\right) / \rho U_{2}^{2}$

$R_{\text {gr }}:$ Radial gap ratio $=$ Radial gap $/ r_{2}$. 


\section{Acknowledgments}

The authors wish to acknowledge and thank Tarek Meakhail and Seung O. Park [12] for readily giving the centrifugal fan drawing for their numerical modeling. They also wish to thank Manipal Institute of Technology, Manipal University for providing computational resources for undertaking this study.

\section{References}

[1] M. Ubaldi, P. Zunino, G. Barigozzi, and A. Cattanei, "An experimental investigation of stator induced unsteadiness on centrifugal impeller outflow," Journal of Turbomachinery, vol. 118, no. 1, pp. 41-51, 1996.

[2] W. Qin and H. Tsukamoto, "Theoretical study of pressure fluctuations downstream of a diffuser pump impeller-part 1 : fundamental analysis on rotor-stator interaction," Journal of Fluids Engineering, vol. 119, no. 3, pp. 647-652, 1997.

[3] F. Justen, K. U. Ziegler, and H. E. Gallus, "Experimental investigation of unsteady flow phenomena in a centrifugal compressor vaned diffuser of variable geometry," Journal of Turbomachinery, vol. 121, no. 4, pp. 763-771, 1999.

[4] F. Shi and H. Tsukamoto, "Numerical study of pressure fluctuations caused by impeller-diffuser interaction in a diffuser pump stage," Journal of Fluids Engineering, vol. 123, no. 3, pp. 466-474, 2001.

[5] M. Sinha and J. Katz, "Quantitative visualization of the flow in a centrifugal pump with diffuser vanes-I: on flow structures and turbulence," Journal of Fluids Engineering, vol. 122, no. 1, pp. 97-107, 2000.

[6] M. Sinha, J. Katz, and C. Meneveau, "Quantitative visualization of the flow in a centrifugal pump with diffuser vanesII: addressing passage-averaged and large-eddy simulation modeling issues in turbomachinery flows," Journal of Fluids Engineering, vol. 122, no. 1, pp. 108-116, 2000.

[7] T. Meakhail, L. Zhang, Z. H. Du, H. P. Chen, and W. Jansen, "The application of PIV in the study of impeller-diffuser interaction in centrifugal fan-part I: impeller-vaneless diffuser interaction," in Proceedings of the ASME International Mechanical Engineering Congress and Exposition (IMECE '01), pp. 235-242, New York, NY, USA, November 2001.

[8] T. Meakhail, L. Zhang, Z. H. Du, H. P. Chen, and W. Jansen, "The application of PIV in the study of impeller diffuser interaction in centrifugal fan-part II: impeller-vaned diffuser interaction," in Proceedings of the ASME International Mechanical Engineering Congress and Exposition (IMECE '01), pp. 243-250, New York, NY, USA, November 2001.

[9] K. U. Ziegler, H. E. Gallus, and R. Niehuis, "A study on impeller-diffuser interaction-part II: detailed flow analysis," Journal of Turbomachinery, vol. 125, no. 1, pp. 183-192, 2003.

[10] F. Akinori and T. Hisasada, "Pressure fluctuation in a vaned diffuser downstream from a centrifugal pump impeller," International Journal of Rotating Machinery, vol. 9, no. 4, pp. 285-292, 2003.

[11] M. M. Cui, "Comparative study of unsteady flows in a transonic centrifugal compressor with vaneless and vaned diffusers," International Journal of Rotating Machinery, vol. 2005, no. 1, pp. 90-103, 2005.

[12] T. Meakhail and S. O. Park, "A study of impeller-diffuservolute interaction in a centrifugal fan," Journal of Turbomachinery, vol. 127, no. 1, pp. 84-90, 2005.
[13] J. Feng, F.-K. Benra, and H. J. Dohmen, "Numerical investigation on pressure fluctuations for different configurations of vaned diffuser pumps," International Journal of Rotating Machinery, vol. 2007, Article ID 34752, 10 pages, 2007.

[14] S. Khelladi, S. Kouidri, F. Bakir, and R. Rey, "Flow study in the impeller-diffuser interface of a vaned centrifugal fan," Journal of Fluids Engineering, vol. 127, no. 3, pp. 495-502, 2005.

[15] K. Majidi, "Numerical study of unsteady flow in a centrifugal pump," Journal of Turbomachinery, vol. 127, no. 2, pp. 363371,2005 .

[16] S. Ibaraki, T. Matsuo, and T. Yokoyama, "Investigation of unsteady flow field in a vaned diffuser of a transonic centrifugal compressor," Journal of Turbomachinery, vol. 129, no. 4, pp. 686-693, 2007.

[17] “FLUENT 6.3," Fluent Inc., Lebanon, NH, USA, 2006.

[18] S. M. Yahya, Turbines, Compressors and Fans, McGraw Hill, New York, NY, USA, 2nd edition, 2005. 

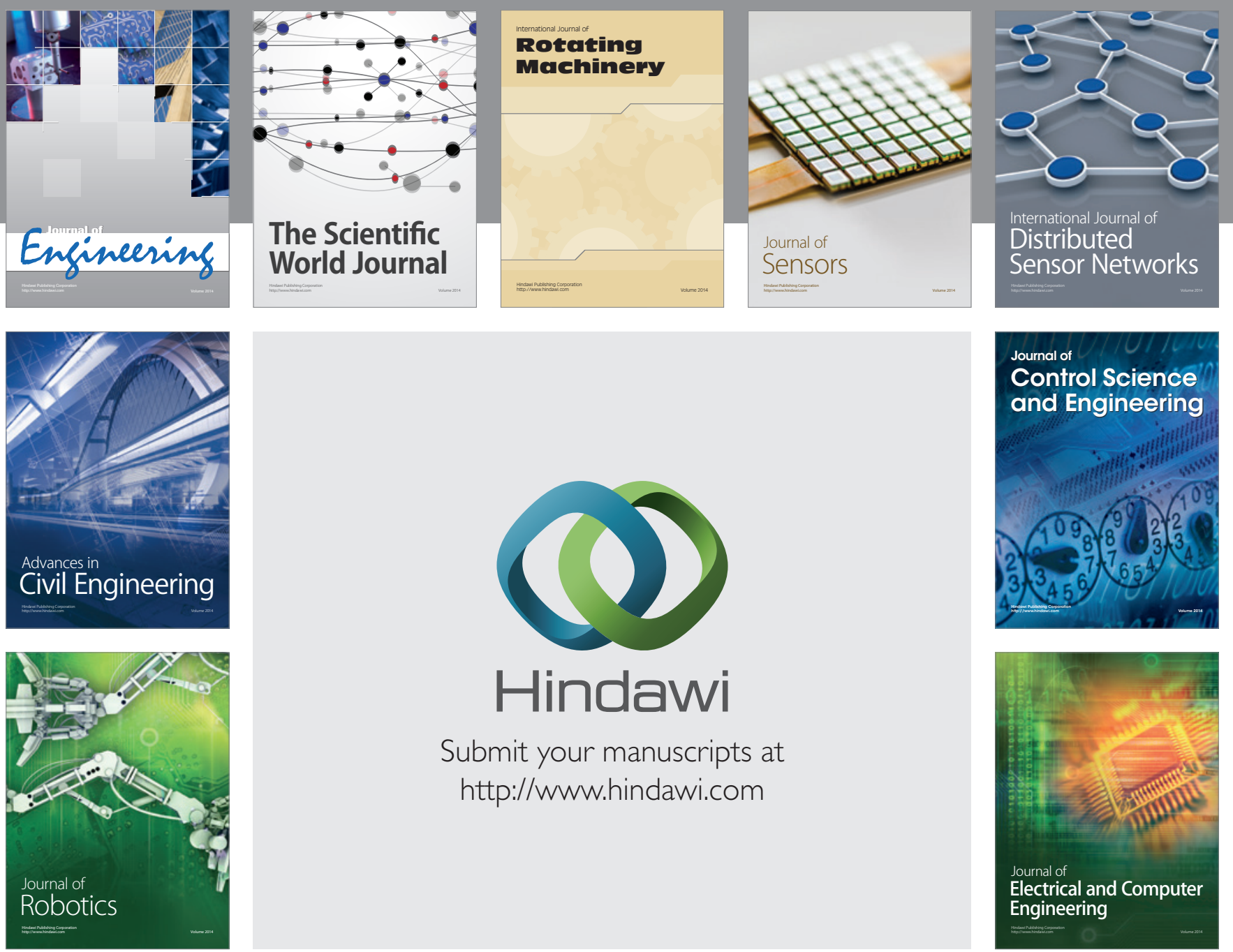

Submit your manuscripts at

http://www.hindawi.com
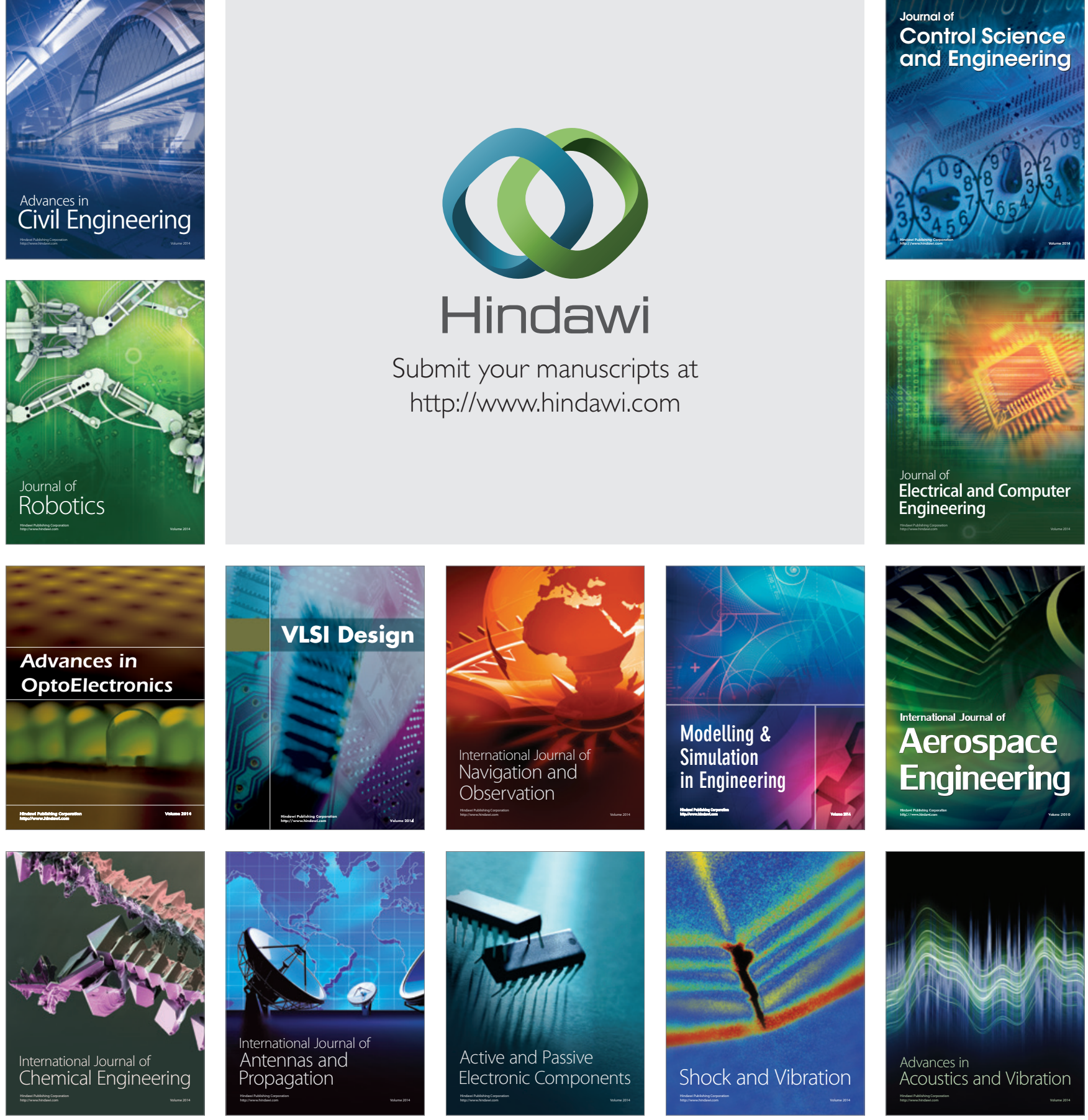